\title{
Factors Contributing to Erythropoietin Hyporesponsiveness in Patients on Long-Term Continuous Ambulatory Peritoneal Dialysis: A Cross-Sectional Study
}

\author{
Takashi Hara Hideyuki Mukai Takafumi Nakashima Rikako Sagara \\ Masahide Furusho Shuhei Miura Jiro Toyonaga Koji Sugawara \\ Kazuhito Takeda \\ Department of Nephrology and Kidney Center, Aso-Iizuka Hospital, Iizuka City, Japan
}

\author{
Key Words \\ Erythropoietin hyporesponsiveness - Erythropoietin resistance index · Long-term continuous \\ ambulatory peritoneal dialysis · Extracellular water/total body water
}

\begin{abstract}
Background: Factors contributing to erythropoietin (EPO) hyporesponsiveness in patients on long-term continuous ambulatory peritoneal dialysis are not well understood. Therefore, we investigated the factors contributing to EPO hyporesponsiveness using the EPO resistance index (ERI). Methods: A total of 14 patients ( 7 males and 7 females, age $65.0 \pm 11.9$ years) were selected for this study. We defined ERI as the weekly dose of EPO per body weight divided by hemoglobin $(\mathrm{U} / \mathrm{kg} / \mathrm{g} / \mathrm{dl} /$ week). Bioelectrical impedance analysis was used to assess the patients' body composition and fluid status. We examined associations between ERI and clinical parameters, such as physiological, chemical and nutrition status, by correlation and multiple linear regression analyses. Results: Peritoneal dialysis duration was $95 \pm 23$ months, and all patients underwent peritoneal dialysis for $>5$ years. Hemoglobin, blood pressure and ultrafiltration volume of peritoneal dialysis were $11.5 \pm 1.2 \mathrm{~g} / \mathrm{dl}, 123 \pm 14 / 72 \pm 8 \mathrm{~mm} \mathrm{Hg}$ and $834 \pm 317 \mathrm{ml} /$ day, respectively. Renal Kt/V and peritoneal Kt/V, which are indices of dialysis adequacy, were $0.32 \pm 0.31$ and $1.70 \pm 0.31$, respectively. Age and extracellular water/total body water (ECW/TBW) ratio had significant positive correlations with ERI (both $p<0.05$ ). Levels of C-reactive protein, serum albumin, parathyroid hormone and normalized protein catabolic rate were not significantly correlated with ERI. In a multiple regression analysis, ECW/TBW was independently associated with ERI $(p<0.05)$. Conclusions: This study demonstrates that ECW/TBW was a factor contributing to ERI and that appropriate maintenance of body fluid volume could contribute to low EPO dosing.




\section{Introduction}

Anemia is a common complication of advanced chronic kidney disease. Decreased production of erythropoietin (EPO) is the primary cause of renal anemia. Erythropoiesisstimulating agents (ESAs) were first approved by the US Food and Drug Administration in June 1989 to treat renal anemia. In Japan, clinical application started in 1990. ESA use in patients with renal anemia undergoing hemodialysis (HD) demonstrated a reduced requirement for blood transfusions and improved quality of life [1,2]. Anemia has been associated with increased mortality rate and cardiovascular events in both dialyzed and nondialyzed patients with chronic kidney disease [3, 4]. Several studies have reported that $90-95 \%$ of dialysis patients responded to EPO in a dose-dependent manner, whereas the remaining $5-10 \%$ of patients had low or absent response [5-7]. The National Kidney Foundation Kidney Disease Outcomes Quality Initiative (NKF KDOQI) defined hyporesponsiveness to EPO as the presence of at least one of the following conditions: (1) a significant decrease in hemoglobin level at a constant EPO dose, (2) a significant increase in the EPO dose required to preserve a certain hemoglobin level, or (3) a failure to raise the hemoglobin level to $>11 \mathrm{~g} / \mathrm{dl}$ despite an EPO dose equivalent to EPO $>500 \mathrm{IU} / \mathrm{kg} /$ week [8].

Among patients undergoing HD, the various factors related to EPO hyporesponsiveness include inflammation status, nutrition status and dialysis adequacy [9-13]. Regarding the management of renal anemia in peritoneal dialysis, we suppose that the amount of EPO required increases as residual renal function declines. Little is known regarding EPO hyporesponsiveness in patients on long-term peritoneal dialysis. The EPO resistance index (ERI) is a helpful parameter in assessing the body's response to EPO. We used ERI as the indicator of EPO hyporesponsiveness and examined the associations between ERI and physiological, chemical and nutritional clinical parameters by correlation and multiple linear regression analyses. The aim of this study was to investigate factors contributing to EPO hyporesponsiveness in patients on long-term peritoneal dialysis.

\section{Subjects and Methods}

This cross-sectional study comprised 14 patients, all on peritoneal dialysis for $>5$ years. We excluded patients with a history of inpatient treatment, infection, bleeding or transfusion within the last month. In accordance with the Japan Society for Dialysis Therapy guidelines, hemoglobin level was controlled between 11.0 and $13.0 \mathrm{~g} / \mathrm{dl}$. We applied the weekly EPO dose as the average value during the last 4 weeks. We obtained blood samples from our outpatient department and measured the samples in our hospital's laboratory. ERI was defined as the weekly dose of EPO per body weight divided by hemoglobin (U/kg/g/dl/week) = weekly $\mathrm{EPO}$ dose $/($ weight $\times \mathrm{Hb}$ ).

In this study, the ESAs used were darbepoetin alfa and epoetin beta pegol. To standardize EPO dose, we standardized the dose of darbepoetin alfa and epoetin beta pegol to epoetin using a conversion factor of $1: 200$.

To predict EPO responsiveness, we measured the following parameters in the following categories: (1) inflammatory markers, such as serum C-reactive protein (CRP) levels, (2) indicators of nutrition status, such as serum albumin levels and normalized protein catabolic rate (nPCR), (3) measures of dialysis adequacy, such as total weekly Kt/V, (4) indicators of fluid volume status, such as extracellular water/total body water (ECW/TBW), (5) markers of chronic kidney disease-related mineral bone disorder, such as serum calcium, serum phosphorus and intact parathyroid hormone (PTH) levels, and (6) arteriosclerosis markers, such as ankle brachial pressure index and brachial-ankle pulse wave velocity. 
Table 1. Characteristics of the patients on long-term continuous ambulatory peritoneal dialysis
Hara et al.: Factors Contributing to Erythropoietin Hyporesponsiveness in Patients on Long-Term Continuous Ambulatory Peritoneal Dialysis: A Cross-Sectional Study

$\begin{array}{lc}\text { Total number of patients } & 14 \\ \text { Age, years } & 65.0 \pm 11.9 \\ \text { Female gender } & 7(50.0 \%) \\ \text { Duration of dialysis, months } & 95 \pm 23 \\ \text { Cause of kidney disease } & \\ \quad \text { Chronic glomerulonephritis } & 10(71.4 \%) \\ \quad \text { Diabetic nephropathy } & 2(14.3 \%) \\ \quad \text { Hypertensive nephrosclerosis } & 1(7.1 \%) \\ \quad \text { Polycystic kidney disease } & 1(7.1 \%) \\ \text { Permeability of the peritoneal membrane } & \\ \quad \text { High average } & 2(14.3 \%) \\ \quad \text { Low average } & 9(64.2 \%) \\ \quad \text { Low } & 3(21.4 \%) \\ \text { Renal Kt/V } & 0.32 \pm 0.31 \\ \text { Peritoneal Kt/V } & 1.70 \pm 0.31 \\ \text { Ultrafiltration volume of peritoneal dialysis, ml/day } & 834 \pm 317 \\ \text { Body mass index, kg/m }{ }^{2} & 23.8 \pm 2.3 \\ \text { Body fat percentage, } \% & 25.0 \pm 7.0 \\ \text { ECW/TBW } & 0.397 \pm 0.015 \\ \text { nPCR } & 0.79 \pm 0.20\end{array}$

Total weekly Kt/V and nPCR were calculated by the values of blood urea nitrogen and serum creatinine measured from the collected urine and peritoneal dialysate over $24 \mathrm{~h}$. Total weekly Kt/V was used to evaluate dialysis adequacy.

Bioelectrical impedance analysis was used to assess the patients' body composition and fluid status. They were calculated using InBody720 (Biospace Co., Ltd., Seoul, Korea). Measurements were taken with the peritoneum empty.

Results are expressed as mean \pm SD. The relationships between ERI and clinical parameters, such as physiological, chemical and nutrition status, were assessed using linear regression with Pearson's correlation coefficients. Multiple regression analysis was performed to determine independent predictors for ERI. The variables were studied with stepwise multiple regression analysis using the $\mathrm{F}$ statistic with $\mathrm{p}=0.05$ as a criterion for significance. Statistical analyses were performed with the statistical software JMP9 (SAS Institute, Cary, N.C., USA). $p<0.05$ with two tails was considered statistically significant.

\section{Results}

The study population comprised 14 long-term peritoneal dialysis patients ( 7 males and 7 females, age $65.0 \pm 11.9$ years). Duration of dialysis was $95 \pm 23$ months. The cause of endstage renal disease was chronic glomerulonephritis in 10 patients, diabetic nephropathy in 2 , hypertensive nephrosclerosis in 1 and polycystic kidney disease in 1 . Table 1 shows the patient characteristics.

The mean hemoglobin value was $11.5 \pm 1.2 \mathrm{~g} / \mathrm{dl}$. All patients received treatment with ESAs. ERI was $8.23 \pm 7.25 \mathrm{U} / \mathrm{kg} / \mathrm{g} / \mathrm{dl} /$ week. The patients' laboratory parameters are provided in table 2.

Pearson's correlation analysis revealed that ERI had a statistically significant correlation with age $\left(\mathrm{R}^{2}=0.4110, \mathrm{p}<0.05\right)$, ECW $/$ TBW $\left(\mathrm{R}^{2}=0.5526, \mathrm{p}<0.05\right)$ and creatinine level $\left(\mathrm{R}^{2}=\right.$ $0.3250, \mathrm{p}<0.05)$. Figure 1 shows the relationships between ERI and age, ECW/TBW and creatinine level. CRP, serum albumin, intact PTH and nPCR levels were not significantly correlated with ERI. 
Table 2. Clinical, physiological and chemical features of the patients on long-term continuous ambulatory peritoneal dialysis

\begin{tabular}{lc}
\hline Hemoglobin, g/dl & $11.5 \pm 1.2$ \\
Hematocrit, \% & $35 \pm 4$ \\
Creatinine, mg/dl & $11.0 \pm 3.9$ \\
Blood urea nitrogen, mg/dl & $48.4 \pm 15.7$ \\
Ferritin, ng/ml & $81.6 \pm 57.5$ \\
Transferrin saturation, \% & $24.2 \pm 8.6$ \\
Serum albumin, g/dl & $3.3 \pm 0.4$ \\
Serum phosphorus, mg/dl & $4.8 \pm 0.9$ \\
Serum calcium, mg/dl & $10.0 \pm 0.5$ \\
Triglyceride, mg/dl & $217 \pm 252$ \\
Low-density lipoprotein cholesterol, mg/dl & $69 \pm 17$ \\
Intact PTH, pg/ml & $86 \pm 103$ \\
CRP, mg/dl & $0.29 \pm 0.51$ \\
ESAs & \\
$\quad$ Darbepoetin & $9(64.3 \%)$ \\
$\quad$ Epoetin beta pegol & $5(35.7 \%)$ \\
ERI & $8.23 \pm 7.25$ \\
Systolic blood pressure, mm Hg & $123 \pm 14$ \\
Diastolic blood pressure, mm Hg & $72 \pm 8$ \\
Ankle brachial pressure index & $1.10 \pm 0.06$ \\
Brachial-ankle pulse wave velocity, cm/s & $1,707 \pm 741$ \\
Left ventricular ejection fraction, $\%$ & $63 \pm 5$ \\
Left ventricular mass index, g/m ${ }^{2}$ & $105 \pm 26$ \\
E/e' & $11.9 \pm 4.0$ \\
\hline \multicolumn{2}{|}{ E = Early transmitral flow velocity; ${ }^{\prime}=$ early diastolic mitral annular } \\
velocity. \\
\hline
\end{tabular}

Table 3. Multiple regression analysis for ERI

\begin{tabular}{lllll}
\hline & $\begin{array}{l}\text { Assessed } \\
\text { value }\end{array}$ & $\begin{array}{l}\text { Standard } \\
\text { error }\end{array}$ & t value & p value \\
\hline Age & 0.1337292 & 0.157699 & 0.85 & $\begin{array}{l}0.4184 \\
\text { ECW/TBW }\end{array}$ \\
Creatinine & 0.213 .11941 & 118.2293 & 2.65 & 0.0265 \\
& 0.515628 & 0.51554 & 0.43 & 0.677 \\
\hline
\end{tabular}

In a multiple regression analysis, ECW/TBW was independently associated with ERI by the least squares method ( $p=0.0265$; table 3$)$.

\section{Discussion}

In 14 patients on long-term peritoneal dialysis, fluid overload was an independent predictor of hyporesponsiveness to EPO. This contradicts previous studies reporting that CRP was the most important predictor of EPO hyporesponsiveness in peritoneal dialysis patients $[14,15]$.

Chronic inflammation causes iron utilization disorders. Several inflammation cytokines, such as IL- 6 and TNF- $\alpha$, inhibit initial maturation of erythroid precursors [16]. Serum concentrations of high-sensitivity CRP, IL- 6 and TNF- $\alpha$ positively correlate with the required epoetin dose and ERI [17]. Bárány et al. [18] observed that patients with a serum CRP level $\geq 2 \mathrm{mg} / \mathrm{dl}$ required $80 \%$ more epoetin than patients with lower CRP levels. In the present study, CRP 


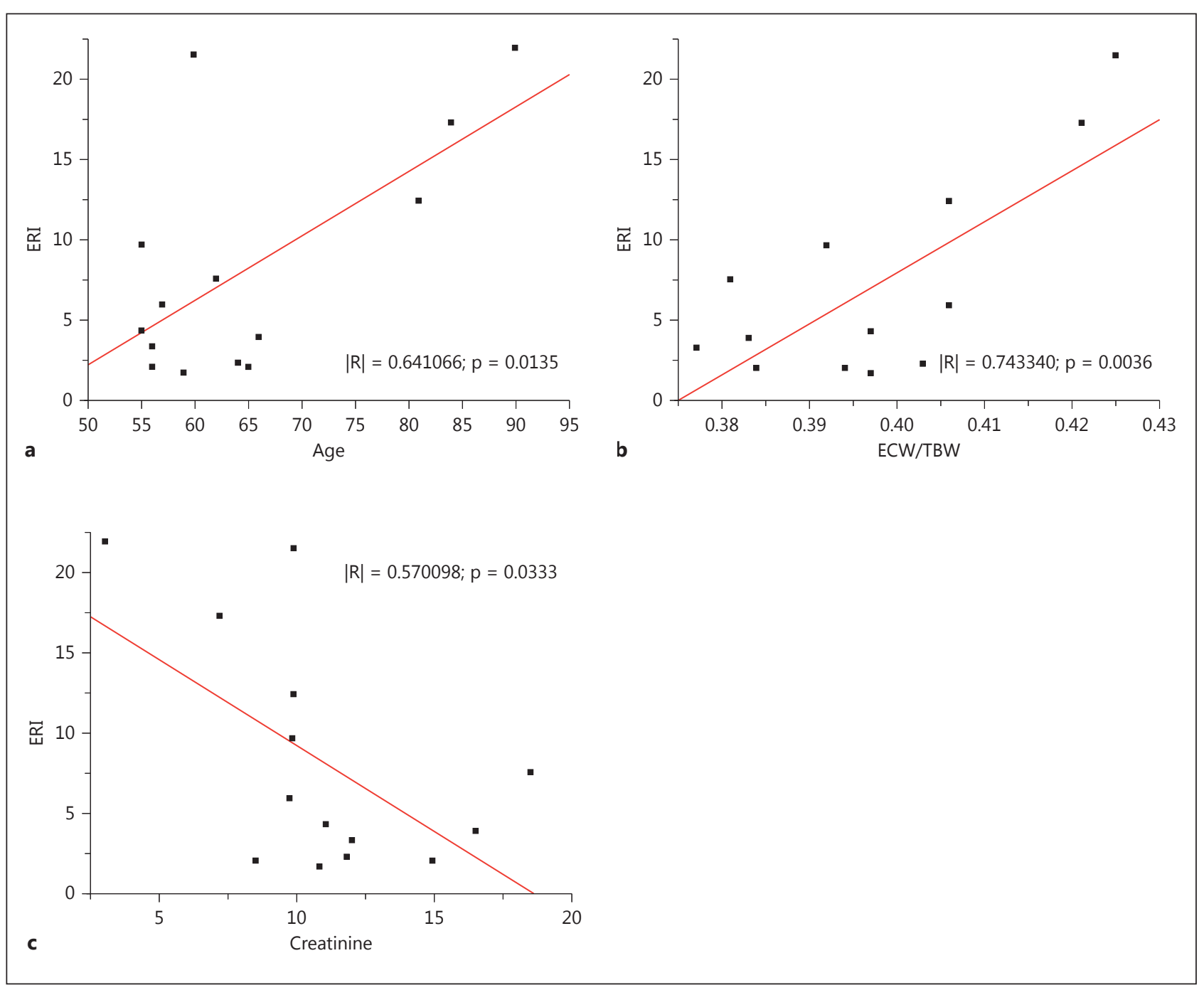

Fig. 1. Correlation between ERI and age (a), ECW/TBW (b) and creatinine (c).

was not significantly correlated with ERI. Selection bias must be considered because we excluded patients with a history of infection in the month prior to the study.

Malnutrition is related to inflammation and arteriosclerosis, and through common mediators, such as TNF- $\alpha$ and IL-6, it may play a relevant role in EPO resistance [19]. The malnutrition-inflammation complex results in incrementally poor responsiveness to EPO [13]. In this study, despite limited protein intake (nPCR $0.79 \pm 0.20 \mathrm{~g} / \mathrm{kg} /$ day), the subjects ingested enough calories $(1,505 \pm 214 \mathrm{kcal} /$ day) and maintained adequate nutrition status (albumin $3.3 \pm 0.4 \mathrm{~g} / \mathrm{dl}$ ). Our finding implies that in stable patients, CRP may not be such an important predictor of EPO hyporesponsiveness.

Hyperparathyroidism is a parameter predictive of EPO hyporesponsiveness [15, 20]. In the present study, no association was found between intact PTH and ERI. Several studies have reported that uremic patients with severe renal anemia significantly improved after parathyroidectomy [21-24]. Furthermore, Battistella et al. [25] found that improved PTH control by cinacalcet was associated with a reduction in darbepoetin requirement in patients with endstage renal disease. In contrast, other studies found no relationship between hyperparathy- 
Hara et al.: Factors Contributing to Erythropoietin Hyporesponsiveness in Patients on Long-Term Continuous Ambulatory Peritoneal Dialysis: A Cross-Sectional Study

roidism and ERI $[6,26]$. Excess secretion of PTH leads to bone marrow fibrosis and consequent interference with erythropoiesis [27]. Altogether, PTH does not directly inhibit human erythropoiesis; instead, bone marrow fibrosis and the uremic environment result in EPO hyporesponsiveness.

We frequently encounter high PTH levels in long-term peritoneal dialysis patients. In our study, the levels of PTH were lower than those in previous studies. We controlled inorganic phosphate, calcium and intact PTH levels over a long period of time using vitamin D pulse therapy and cinacalcet for secondary hyperparathyroidism. In addition, we ensured proper dialysis regimens for patients (renal Kt/V $=0.32 \pm 0.31$, peritoneal Kt $/ \mathrm{V}=1.70 \pm 0.31$ ); therefore, our patients displayed less uremia.

The response to EPO is influenced by body composition. Fat tissue favors the body's response to EPO [28, 29].

The relationship between volume overload and EPO hyporesponsiveness is unclear. Although data demonstrate an association between ECW/TBW and ERI, they cannot offer a causal explanation for it. Volume overload is a common characteristic associated with renal progression in chronic kidney disease. It is an independent predictor of all-cause and cardiovascular mortality in patients undergoing HD as well as patients with other chronic kidney diseases [30, 31]. The abnormal fluid status increases cardiac volume overload, contributing to increased blood pressure and left ventricular hypertrophy. Hypertension is strongly correlated with the exacerbation of renal diseases, cardiovascular comorbidity, and prognosis [32, 33].

In a landmark study, the Trial to Reduce Cardiovascular Events with Aranesp Therapy (TREAT) study examined the use of EPO therapy to treat renal anemia in patients with chronic kidney disease and found no benefit compared with placebo [34]. Mortality rate and cardiovascular events did not differ between the control and therapeutic groups. However, fatal or nonfatal stroke occurred in 101 patients assigned to darbepoetin alfa and 53 patients assigned to placebo (hazard ratio 1.92; 95\% confidence interval 1.38-2.68; $\mathrm{p}<0.001$ ). There was no significant difference in systolic blood pressure between the two groups; the median systolic blood pressure was $134 \mathrm{~mm}$ Hg (interquartile range 126-143) in both groups. Increased systolic blood pressure did not explain the higher incidence of stroke that was likely related to EPO. However, this study did not evaluate fluid status, and it is possible that volume overload contributed to increased stroke incidence. With more strictly controlled blood pressure, the statistical data might have been different. Where there is body fluid overload, the hemoglobin level is reduced by dilution. EPO requirements may increase because of an 'apparent anemia', and the ensuing volume overload may exacerbate blood pressure.

Although peritoneal dialysis is believed to provide better volume control than HD because of its continuous ultrafiltration, volume overload is common in peritoneal dialysis patients. Plum et al. [35] found a higher ECW/TBW ratio in peritoneal dialysis patients compared with HD patients. In our hospital, there are 28 patients (10 males and 18 females, age $67.6 \pm 9.6$ years) who have been on HD for $>10$ years (HD duration $154 \pm 44$ months). Post-HD ECW/ TBW ratios were $0.394 \pm 0.011$. There was no difference in ECW/TBW between peritoneal dialysis and HD patients in our hospital. In the present study, blood pressure was kept low $(123 \pm 14 / 72 \pm 8 \mathrm{~mm} \mathrm{Hg})$ through the maintenance of appropriate volume status. Therefore, we suggest that appropriate fluid regulation can decrease EPO hyporesponsiveness while managing systolic blood pressure.

In 2013 there were 9,245 peritoneal dialysis patients in Japan, 1,794 of whom had been on peritoneal dialysis for $>4$ years [36]. Many facilities avoid peritoneal dialysis for $>5$ years because of the risk of developing encapsulating peritoneal sclerosis. As more facilities increase the duration of peritoneal dialysis, more careful studies are required to define guidelines for long-term care of peritoneal dialysis patients. Our study can help elaborate one way to decrease the use of expensive ESAs. 
Hara et al.: Factors Contributing to Erythropoietin Hyporesponsiveness in Patients on Long-Term Continuous Ambulatory Peritoneal Dialysis: A Cross-Sectional Study

Several limitations should be noted in the interpretation of the study results. First, the ERI data were obtained at a single time point. Since ERI is calculated from several EPO dose, weight and hemoglobin levels, the latter two of which can quite rapidly change, prospective observational studies of peritoneal dialysis patients are required to confirm the relationship. Second, this is a cross-sectional study with a small sample size. We need to confirm the results in a large cohort.

In conclusion, our study shows that fluid overload is an independent predictor of hyporesponsiveness to EPO. Appropriate maintenance of body fluid volume could contribute to lower EPO doses. Prospective randomized controlled trials are needed to evaluate whether strict volume control may improve the mortality rate of peritoneal dialysis.

\section{Acknowledgments}

The authors thank their nurses, registered dieticians, medical engineers, medical staff, doctor secretaries and patients.

\section{References}

$>1$ Eschbach JW, Abdulhadi MH, Browne JK, Delano BG, Downing MR, Egrie JC, Evans RW, Friedman EA, Graber SE, Haley NR, Korbet S, Krantz SB, Lundin AP, Nissenson AR, Ogden DA, Paganini EP, Rader B, Rutsky EA, Stivelman J, Stone WJ, Teschan P, Van Stone JC, Van Wyck DB, Zuckerman K, Adamson JW: Recombinant human EPO in anemic patients with end-stage renal disease: results of a phase III multicenter clinical trial. Ann Intern Med 1989;111:992-1000.

$\checkmark 2$ Association between recombinant human erythropoietin and quality of life and exercise capacity of patients receiving haemodialysis. Canadian Erythropoietin Study Group. BMJ 1990;300:573-578.

-3 Locatelli F, Pisoni RL, Combe C, Bommer J, Andreucci VE, Piera L, Greenwood R, Feldman HI, Port FK, Held PJ: Anaemia in haemodialysis patients of five European countries: association with morbidity and mortality in the Dialysis Outcomes and Practice Patterns Study (DOPPS). Nephrol Dial Transplant 2004;19:121-132.

4 Vlagopoulos PT, Tighiouart H, Weiner DE, Griffith J, Pettitt D, Salem DN, Levey AS, Sarnak MJ: Anemia as a risk factor for cardiovascular disease and all-cause mortality in diabetes: the impact of chronic kidney disease. J Am Soc Nephrol 2005; 16:3403-3410.

-5 Eschbach JW, Egrie JC, Downing MR, Browne JK, Adamson JW: Correction of the anemia of end-stage renal disease with recombinant human erythropoietin. N Engl J Med 1987;316:73-78.

6 Gunnell J, Yeun JY, Depner TA, Kaysen GA: Acute-phase response predicts erythropoietin resistance in hemodialysis and peritoneal dialysis patients. Am J Kidney Dis 1999;33:63-72.

7 Macdougall IC: Poor response to erythropoietin: practical guidelines on investigation and management. Nephrol Dial Transplant 1995;10:607-614.

8 KDOQI; National Kidney Foundation: KDOQI clinical practice guidelines and clinical practice recommendations for anemia in chronic kidney disease. Am J Kidney Dis 2006;47(5 suppl 3):S11-S145.

-9 Kalantar-Zadeh K, Lee GH, Miller JE, Streja E, Jing J, Robertson JA, Kovesdy CP: Predictors of hyporesponsiveness to erythropoiesis-stimulating agents in hemodialysis patients. Am J Kidney Dis 2009;53:823-834.

10 Mallick S, Rafiroiu A, Kanthety R, Iqbal S, Malik R, Rahman M: Factors predicting erythropoietin resistance among maintenance hemodialysis patients. Blood Purif 2012;33:238-244.

11 Regidor DL, Kopple JD, Kovesdy CP, Kilpatrick RD, McAllister CJ, Aronovitz J, Greenland S, Kalantar-Zadeh K: Associations between changes in hemoglobin and administered erythropoiesis-stimulating agent and survival in hemodialysis patients. J Am Soc Nephrol 2006;17:1181-1191.

12 Locatelli F, Andrulli S, Memoli B, Maffei C, Del Vecchio L, Aterini S, De Simone W, Mandalari A, Brunori G, Amato M, Cianciaruso B, Zoccali C: Nutritional-inflammation status and resistance to erythropoietin therapy in haemodialysis patients. Nephrol Dial Transplant 2006;21:991-998.

-13 Rattanasompattikul M, Molnar MZ, Zaritsky JJ, Hatamizadeh P, Jing J, Norris KC, Kovesdy CP, Kalantar-Zadeh $\mathrm{K}$ : Association of malnutrition-inflammation complex and responsiveness to erythropoiesis-stimulating agents in long-term hemodialysis patients. Nephrol Dial Transplant 2013;28:1936-1945.

14 Kim JK, Park BS, Park MJ, Choi W, Ma SK, Nah MY, Yeum CH, Jung K, Lee SC, Kim SW, Kim NH, Kang YJ, Choi KC: The predictive parameters of erythropoietin hyporesponsiveness in patients on continuous ambulatory peritoneal dialysis. Korean J Intern Med 2001;16:110-117.

15 Wei M, Bargman JM, Oreopoulos DG: Factors related to erythropoietin hypo-responsiveness in patients on chronic peritoneal dialysis. Int Urol Nephrol 2007;39:935-940. 
Hara et al.: Factors Contributing to Erythropoietin Hyporesponsiveness in Patients on Long-Term Continuous Ambulatory Peritoneal Dialysis: A Cross-Sectional Study

16 Cooper AC, Mikhail A, Lethbridge MW, Kemeny DM, Macdougall IC: Increased expression of erythropoiesis inhibiting cytokines (IFN-gamma, TNF-alpha, IL-10, and IL-13) by T cells in patients exhibiting a poor response to erythropoietin therapy. J Am Soc Nephrol 2003;14:1776-1784.

$\checkmark 17$ Kalantar-Zadeh K, McAllister CJ, Lehn RS, Lee GH, Nissenson AR, Kopple JD: Effect of malnutrition-inflammation complex syndrome on EPO hyporesponsiveness in maintenance hemodialysis patients. Am J Kidney Dis 2003; 42:761-773.

18 Bárány P, Divino Filho JC, Bergström J: High C-reactive protein is a strong predictor of resistance to erythropoietin in hemodialysis patients. Am J Kidney Dis 1997;29:565-568.

19 Pecoits-Filho R, Lindholm B, Axelsson J, Stenvinkel P: Update on interleukin-6 and its role in chronic renal failure. Nephrol Dial Transplant 2003;18:1042-1045.

20 Al-Hilali N, Al-Humoud H, Ninan VT, Nampoory MRN, Puliyclil MA, Johny KV: Does parathyroid hormone affect erythropoietin therapy in dialysis patients? Med Princ Pract 2007;16:63-67.

21 Fujita Y, Inoue S, Horiguchi S, Kuki A: Excessive level of parathyroid hormone may induce the reduction of recombinant human erythropoietin effect on renal anemia. Miner Electrolyte Metab 1995;21:50-54.

22 Better OS, Shasha SM, Winaver J, Chaimowitz C, Barzilai A, Erlik D: Improvement in the anemia of hemodialyzed patients following parathyroidectomy. Kidney Int 1976;10:487.

23 Barbour GL: Effect of parathyroidectomy on anemia in chronic renal failure. Arch Intern Med 1979;139:889891.

24 Zingraff J, Drüeke T, Marie P, Man NK, Jungers P, Bordier P: Anemia and secondary hyperparathyroidism. Arch Intern Med 1978;138:1650-1652.

25 Battistella M, Richardson RM, Bargman JM, Chan CT: Improved parathyroid hormone control by cinacalcet is associated with reduction in darbepoetin requirement in patients with end-stage renal disease. Clin Nephrol 2011;76:99-103.

26 Komatsuda A, Hirokawa M, Haseyama T, Horiuchi T, Wakui H, Imai H, Miura AB: Human parathyroid hormone does not influence human erythropoiesis in vitro. Nephrol Dial Transplant 1998;13:2088-2091.

-27 Rao DS, Shih MS, Mohini R: Effect of serum parathyroid hormone and bone marrow fibrosis on the response to erythropoietin in uremia. N Engl J Med 1993;328:171-175.

-28 Kotanko P, Thijssen S, Levin NW: Association between erythropoietin responsiveness and body composition in dialysis patients. Blood Purif 2008;26:82-89.

-29 Vega A, Ruiz C, Abad S, Quiroga B, Velázquez K, Yuste C, Aragoncillio I, López Gómez JM: Body composition affects the response to erythropoiesis-stimulating agents in patients with chronic kidney disease in dialysis. Ren Fail 2014;36:1073-1077.

-30 Tsai YC, Chiu YW, Tsai JC, Kuo HT, Hung CC, Hwang SJ, Chen TH, Kuo MC, Chen HC: Association of fluid overload with cardiovascular morbidity and all-cause mortality in stages 4 and 5 CKD. Clin J Am Soc Nephrol 2015;10: 39-46.

-31 Wizemann V, Wabel P, Chamney P, Zaluska W, Moissl U, Rode C, Malecka-Masalska T, Marcelli D: The mortality risk of overhydration in haemodialysis patients. Nephrol Dial Transplant 2009;24:1574-1579.

32 Jafar TH, Schmid CH, Landa M, Giatras I, Toto R, Remuzzi G, Maschio G, Brenner BM, Kamper A, Zucchelli P, Becker G, Himmelmann A, Bannister K, Landais P, Shahinfar S, de Jong PE, de Zeeuw D, Lau J, Levey AS: Angiotensin-converting enzyme inhibitors and progression of nondiabetic renal disease. A meta-analysis of patientlevel data. Ann Intern Med 2001;135:73-87.

-33 Takeda A, Toda T, Fujii T, Shinohara S, Sasaki S, Matsui N: Discordance of influence of hypertension on mortality and cardiovascular risk in hemodialysis patients. Am J Kidney Dis 2005;45:112-118.

-34 Pfeffer MA, Burdmann EA, Chen CY, Cooper ME, de Zeeuw D, Eckardt KU, Feyzi JM, Ivanovich P, Kewalramani R, Levey AS, Lewis EF, McGill JB, McMurray JJ, Parfrey P, Parving HH, Remuzzi G, Singh AK, Solomon SD, Toto R; TREAT Investigators: A trial of darbepoetin alfa in type 2 diabetes and chronic kidney disease. N Engl J Med 2009;361:2019-2032.

-35 Plum J, Schoenicke G, Kleophas W, Kulas W, Steffens F, Azem A, Grabensee B: Comparison of body fluid distribution between chronic haemodialysis and peritoneal dialysis patients as assessed by biophysical and biochemical methods. Nephrol Dial Transplant 2001;16:2378-2385.

36 The Japanese Society for Dialysis Therapy: Current status of Japan's chronic dialysis therapy (in Japanese). http://docs.jsdt.or.jp/overview/index.html. 